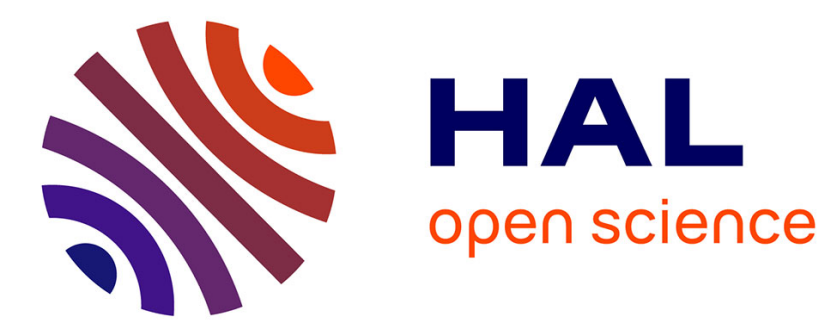

\title{
A mechanistic approach to the Kitagawa-Takahashi diagram using a multiaxial probabilistic framework
}

Etienne Pessard, Daniel Bellett, Franck Morel

\section{To cite this version:}

Etienne Pessard, Daniel Bellett, Franck Morel. A mechanistic approach to the Kitagawa-Takahashi diagram using a multiaxial probabilistic framework. Engineering Fracture Mechanics, 2013, 109, pp.89-104. 10.1016/j.engfracmech.2013.06.001 . hal-00875771

\section{HAL Id: hal-00875771 \\ https://hal.science/hal-00875771}

Submitted on 22 Oct 2013

HAL is a multi-disciplinary open access archive for the deposit and dissemination of scientific research documents, whether they are published or not. The documents may come from teaching and research institutions in France or abroad, or from public or private research centers.
L'archive ouverte pluridisciplinaire HAL, est destinée au dépôt et à la diffusion de documents scientifiques de niveau recherche, publiés ou non, émanant des établissements d'enseignement et de recherche français ou étrangers, des laboratoires publics ou privés. 


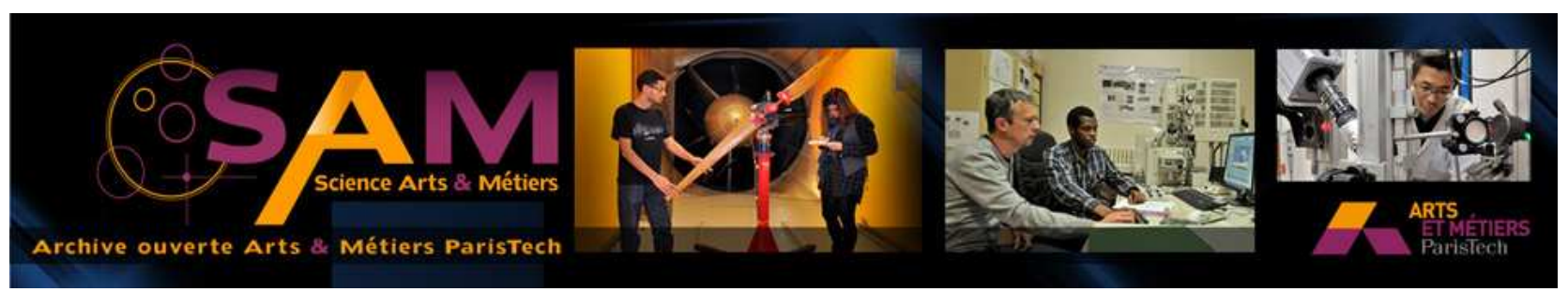

Science Arts \& Métiers (SAM)

is an open access repository that collects the work of Arts et Métiers ParisTech researchers and makes it freely available over the web where possible.

This is an author-deposited version published in: http://sam.ensam.eu

Handle ID: .http://hdl.handle.net/10985/7416

\section{To cite this version :}

Etienne PESSARD, Daniel BELLETT, Franck MOREL, Imade KOUTIRI - A mechanistic approach to the Kitagawa-Takahashi diagram using a multiaxial probabilistic framework - Engineering Fracture Mechanics - Vol. 109, p.89-104 - 2013 


\title{
A mechanistic approach to the Kitagawa-Takahashi diagram using a multiaxial probabilistic framework
}

\author{
Etienne Pessard ${ }^{\mathrm{a}, *}$, Daniel Bellett ${ }^{\mathrm{a}}$, Franck Morel $^{\mathrm{a}}$, Imade Koutiri ${ }^{\mathrm{a}}$ \\ ${ }^{a}$ LAMPA, Arts et Métiers ParisTech Angers, 2 Bd du Ronceray, 49035 Angers Cedex 01
}

\begin{abstract}
The aim of this paper is to propose a flexible multiaxial modelling framework that is capable of combining two fatigue damage mechanisms so as to continuously describe the KitagawaTakahashi diagram. It is proposed that this diagram represents two distinct fatigue damage mechanisms: one associated with crack initiation (or microstructurally small cracks) and the other with crack propagation (or long cracks). It is further postulated that these damage mechanisms are more appropriately modelled using different fatigue criteria. A probabilistic modelling framework is proposed in which any two suitable fatigue criteria can be combined in order to simultaneously model both damage mechanisms and the transition between them. This framework is based on the weakest link hypothesis and results in a probabilistic Kitagawa-Takahashi type diagram.

Keywords: Probabilistic Kitagawa-Takahashi diagram, Fatigue damage mechanisms, High cycle fatigue, Small crack problem, Defects
\end{abstract}

\section{Introduction}

In terms of High Cycle Fatigue (HCF), it is well known in the engineering community that different fatigue design philosophies exist and that the choice of a certain philosophy strongly depends on the application under consideration. Two of the more widely used design philosophies are (a) the safe-life approach and (b) the damage tolerance approach. The safe-life approach is one of the oldest strategies and has the simple objective of ensuring that a component will never fail during its design life. This approach is often used, for example, in the automotive industry

\footnotetext{
*Corresponding author. Tel.: +332412073 79; fax: +33241207320.

Email address: etienne.pessard@angers. ensam.fr (Etienne Pessard)
} 
and can be thought of as controlling the phenomenon of fatigue crack initiation. The damage tolerance approach on the other hand assumes that fatigue cracks exist and that this damage will be controlled by an imposed maintenance regime to ensure that fatigue cracks never reach their critical size. In this approach the focus is on crack propagation.

In the same manner the development of fatigue criteria has also followed two essentially parallel paths. The safe-life approach is often implemented via the application of so-called multiaxial fatigue criteria [1, 2, 3, 4, 5], capable of predicting crack initiation due to complicated in-service multiaxial loading conditions. The damage tolerance approach, on the other hand, is championed by fracture mechanics. In the scientific literature there is surprisingly little overlap between these two different approaches, which are essentially different aspects of the same engineering problem (i.e. design against fatigue).

The basic premise of this article is that these two modelling approaches co-exist because they model two very different fatigue damage mechanisms. One associated with crack initiation and the other with crack propagation. This by itself is not new, however the innovation in this work is the proposition of a flexible modelling framework in which it is possible to combine two completely different fatigue criteria in order to model multiple damage mechanisms.

The mechanism of fatigue crack initiation in polycrystalline metallic materials has long been understood and is discussed in most good fatigue textbooks [6]. Essentially, crack initiation is due to localised plasticity (or dislocation movement) in well orientated slip systems of isolated surface grains. This irreversible plastic slip leads to the formation of persistent slip bands that can be often observed on the surface of the material and result in the creation of intrusions and extrusions. These are essentially small peaks and valleys that increase the surface roughness and introduce small stress concentrations that eventually lead to the development of micro-cracks. The important things to note are: (a) the initiation process is controlled by localised plasticity (b) that micro-cracks are initiated on crystalline slip planes and (c) that these planes are in general aligned with the planes of maximum shear stress amplitude.

When it comes to crack propagation mechanisms, Forsyth [7] proposed in 1962 that crack growth can be divided into two stages. When the crack and the zone of plastic deformation surrounding the crack tip are confined to within a few grain diameters, crack growth occurs predom- 
inately by single shear, in the direction of the primary slip system. This single slip mechanism, leading to a zig-zag crack path, has been termed stage I crack growth. For longer length cracks, for which the crack tip plastic zone encompasses many grains, the crack propagation mechanism involves simultaneous or alternating plastic flow along two slip systems. This duplex slip mechanism, termed stage II by Forsyth [7] results in a planar (mode I) crack path normal to the far field tensile axis [6].

It is important to note that stage I crack growth (like the mechanism of crack initiation) is controlled by the shear stress on a crystallographic slip plane. In terms of Linear Elastic Fracture Mechanics (LEFM) terminology, this is often referred to as Mode II crack opening. On the other hand stage II growth is dominated by the normal stress perpendicular to the crack (or Mode I crack opening). Therefore, from a mechanistic point of view it is not surprising that crack initiation and stage I propagation are more appropriately modelled by multiaxial fatigue criteria in which the shear stress (on a critical plane for example) is a major ingredient of the criterion, while stage II crack growth is better modelled by fracture mechanics approaches, which are largely focused on mode I propagation.

Linear Elastic Fracture Mechanics (LEFM) has achieved great success in modelling long crack fatigue behaviour. However, it is well known that classical LEFM predictions greatly overestimate the residual fatigue strength of cracked bodies containing micro-structurally short cracks. This is often referred to as the short crack problem and was first highlighted by Kitagawa and Takahashi [8] who presented it in the form of their now famous Kitagawa-Takahashi diagram (see Figure 1). They showed that experimental fatigue data could be described by two lines, one representing the plain specimen fatigue strength and the other the LEFM prediction using the crack propagation threshold, $\Delta K_{t h}$. The validity of this diagram has been confirmed by numerous investigations for many different materials [4, 9, 10, 11].

What should be noted is that the Kitagawa diagram can be divided into three different zones:

- Zone 1: When a crack can be classified as micro-structurally small the fatigue strength is controlled by the initiation damage mechanism, in which the damage is due to microplasticity in single slip systems. The shear stress on the slip plane is the dominate driving 


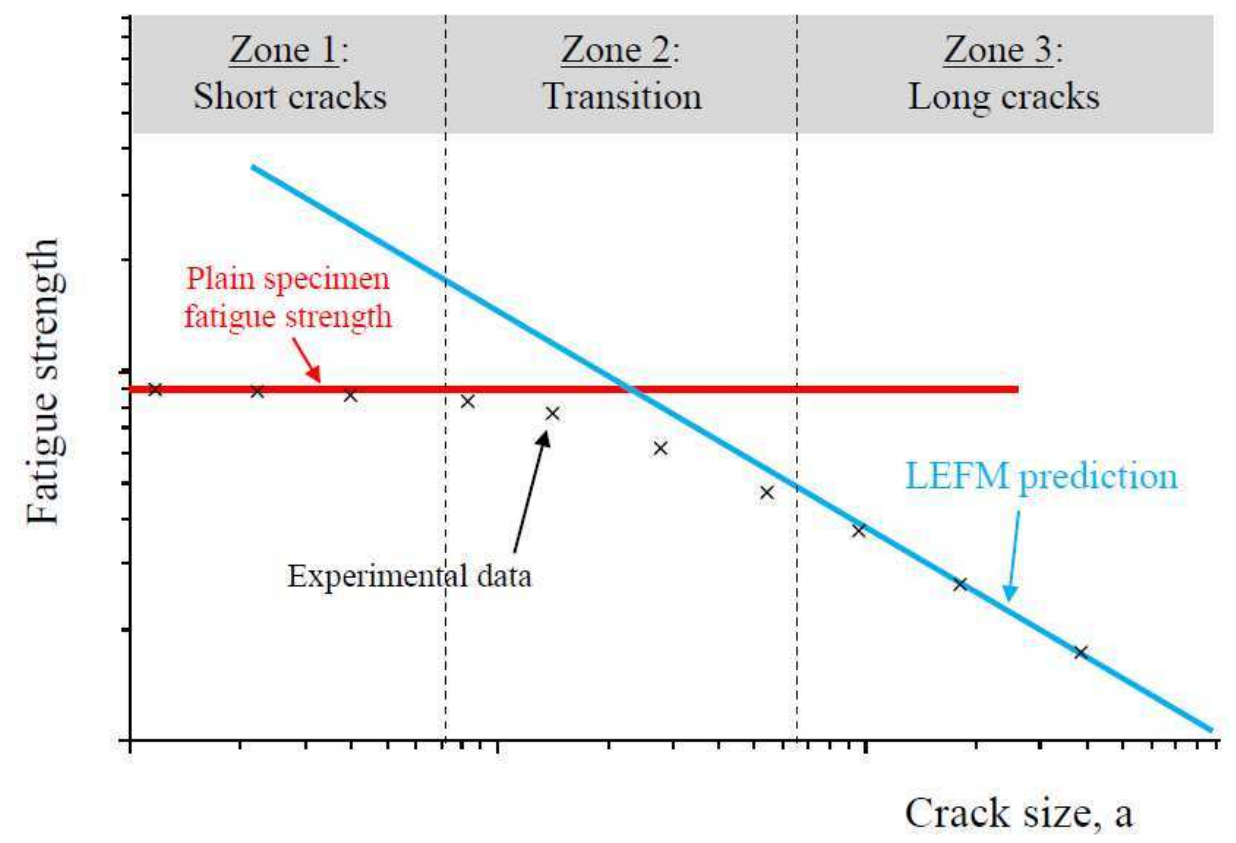

Fig. 1: Schematic representation of the Kitagawa-Takahashi diagram

force. In this zone, the fatigue phenomenon is most appropriately modelled by the class of fatigue criteria defined as multiaxial above.

- Zone 2: is a transition zone between the two damages mechanisms. In this zone neither damage mechanism is dominate. A state of competition is found between the two damage mechanisms, which are both activated.

- Zone 3: When cracks or defects achieve a size that is sufficiently large so that the fatigue process zone ahead of the crack tip encompasses many grains, the fatigue strength is controlled by the ability of the microstructure to any stop further crack propagation. In this respect microstructural heterogeneities (i.e. grain boundaries, different phases, precipices, etc.) play a major role and act as barriers to crack growth. When this damage mechanism is the driving force for crack growth, crack tend to propagate on planes of maximum normal stress. Hence, LEFM type fatigue criteria are appropriate for modelling the fatigue behaviour. 
In the previous discussion the terms crack initiation damage mechanism and crack propagation damage mechanism have been used, however it must be kept in mind that we are talking about fatigue. Hence, the terms non-initiation and crack arrest would be more appropriate. In the following the term mechanism 1 will be used to describe the crack initiation damage mechanism and mechanism 2 will be used to describe the crack propagation damage mechanism. Note also that this work is focused on the high cycle fatigue domain in which it is more appropriate to use the terminology fatigue strength corresponding to a fixed number of cycles, than the term fatigue limit.

The discussion above is centred around fatigue damage mechanisms observed in relatively homogeneous polycrystalline metallic materials. However, real metallic materials often contain microstructural heterogeneities, many of which can be classified as material defects. Two striking examples are the presence of micro-shrinkage pores in cast aluminium alloys [12, 13] and clusters of elongated $\mathrm{MnS}$ inclusions in forged steels [14, 15, 16]. In these cases the distinction between the two fatigue damage mechanisms is less clear. Concretely, the presence of large material defects can result in the crack propagation mechanism (mechanism 2) always being dominate. Therefore, the correct identification of the dominate damage mechanism is extremely important and the determination of a Kitagawa-Takahashi diagram is essential for establishing correct fatigue predictions. The application of the proposed modelling framework to these two cases is discussed in the last section of the paper.

As already stated, the aim of this article is to present a flexible modelling framework in which both damage mechanisms can be simultaneously modelled using two different fatigue criteria. The basic ingredients of this framework are:

1. The choice of two appropriate fatigue criteria to model the two damage mechanisms.

2. The threshold quantities of both criteria are defined in terms of Weibull distributions. This allows the experimentally observed scatter to be taken into account and associates a probability of failure with each criterion (and damage mechanism).

3. The weakest link hypothesis is then used to determine the total probability of failure due to both damage mechanisms. This leads to a continuous transition between the predictions 
from the two criteria.

This framework results in probabilistic Kitagawa-Takahashi diagrams and if multiaxial fatigue criteria are used, Kitagawa-Takahashi diagrams can be established for any multiaxial stress state. In the following this framework will be demonstrated using three different criteria combinations and is applied to multiaxial fatigue data taken from the literature.

\section{The probabilistic modelling framework}

It is important to realise that the focus here is on the modelling framework and that any two appropriate fatigue criteria can be used within this framework. It is sufficient to define one criterion to describe the crack initiation damage mechanism (mechanism 1) and another for the crack propagation mechanism (mechanism 2).

It should also be recognised that the original Kitagawa-Takahashi diagram is indeed exactly this. The two lines of the diagram represent two distinct criteria: the LEFM criterion and a simple maximum stress amplitude criterion, combined in a deterministic manner.

\subsection{Probabilistic modelling of mechanism 1}

This section is devoted to the modelling of the crack initiation damage mechanism (mechanism 1). In particular, the focus is on transgranular initiation in a polycrystalline aggregate free of geometric defects or cracks.

Over the years many modelling approaches have been proposed to determine the possibility of crack initiation. Table 1 summarises several high cycle fatigue criteria that could be used in the proposed framework. Note that the first criterion is the simple stress amplitude criterion, which for uniaxial loads corresponds to the amplitude of the maximum principal stress. Even though the maximum principal stress criterion is not well suited to model the fatigue behaviour of ductile material, this criteria is chosen for his simplicity and is used below to explain the proposed methodology . The last three criterion in Table 1 are well known multiaxial criteria that have been proposed to take into account complex cyclic loading conditions.

As a general rule most fatigue criteria can be defined by an equivalent mechanical quantity (i.e. stress, strain, energy, etc.), which is compared to a threshold quantity, for a given number of 
cycles. Crack initiation is subsequently predicted if the equivalent quantity is greater than or equal to the threshold quantity (see equation 1). In the following, for convenience, these will be referred to stress quantities. Hence, the condition for crack initiation is defined by:

$$
\sigma_{e q} \geqslant \sigma_{t h}
$$

\begin{tabular}{l|l|l} 
Criterion & Equivalent Stress $\sigma_{e q}$ & Threshold $\sigma_{t h}$ \\
\hline Stress amplitude & $\sigma_{I, a}$ & $s_{-1}$ \\
Fatemi-Socie [3] & $\Delta \gamma\left(1+k_{F S} \frac{\sigma_{n, \max }}{\sigma_{y}}\right)$ & $\beta_{F S}$ \\
Crossland [17] & $\sqrt{J_{2, a}}+k \sigma_{H, \max }$ & $\lambda$ \\
Dang Van [18, 19] & $\max _{\vec{n}}\left[\max _{t}\left[\tau_{\text {meso }}+\alpha_{D V} \sigma_{H}\right]\right.$ & $\beta_{D V}$ \\
\hline
\end{tabular}

Table 1: Stress amplitude criterion and three well known fatigue criteria divided into equivalent and threshold parts (N.B. all symbols are defined in the nomenclature)

In order to take into account the inherent stochastic nature of the fatigue phenomenon it is proposed, as part of the modelling framework, to use a two parameter Weibull distribution [20, 21] to describe the threshold stress. In this work the Weibull distribution is used because it is easily applicable to the weakest link theory.

This choice then makes it possible to define the probability of crack initiation within a grain. Equation 2 shows the probability density function used to define the threshold stress.

$$
f_{01}\left(\sigma_{t h}\right)=\frac{m_{1}}{\sigma_{t h 01}}\left(\frac{\sigma_{t h}}{\sigma_{t h 01}}\right)^{m_{1}-1} \exp -\left(\frac{\sigma_{t h}}{\sigma_{t h 01}}\right)^{m_{1}}
$$

Where $\sigma_{t h 01}$ is the scale parameter and $m_{1}$ is the shape parameter (or the Weibull exponent) used to reflect the scatter associated with the threshold stress and by consequence the scatter associated with the fatigue damage mechanism (see Figure 2). The probability of microcrack initiation in a grain corresponds to the probability of finding a grain with a threshold stress $\sigma_{t h}$ that is less than the applied equivalent stress $\sigma_{e q}$. This can be expressed as: 


$$
\begin{gathered}
P_{F_{01}}=\left(\sigma_{t h}<\sigma_{e q}\right)=\int_{0}^{\sigma_{e q}} f_{01}\left(\sigma_{t h}\right) d \sigma_{t h} \\
P_{F_{01}}=1-\exp \left[-\left(\frac{\sigma_{e q}}{\sigma_{t h 01}}\right)^{m_{1}}\right]
\end{gathered}
$$
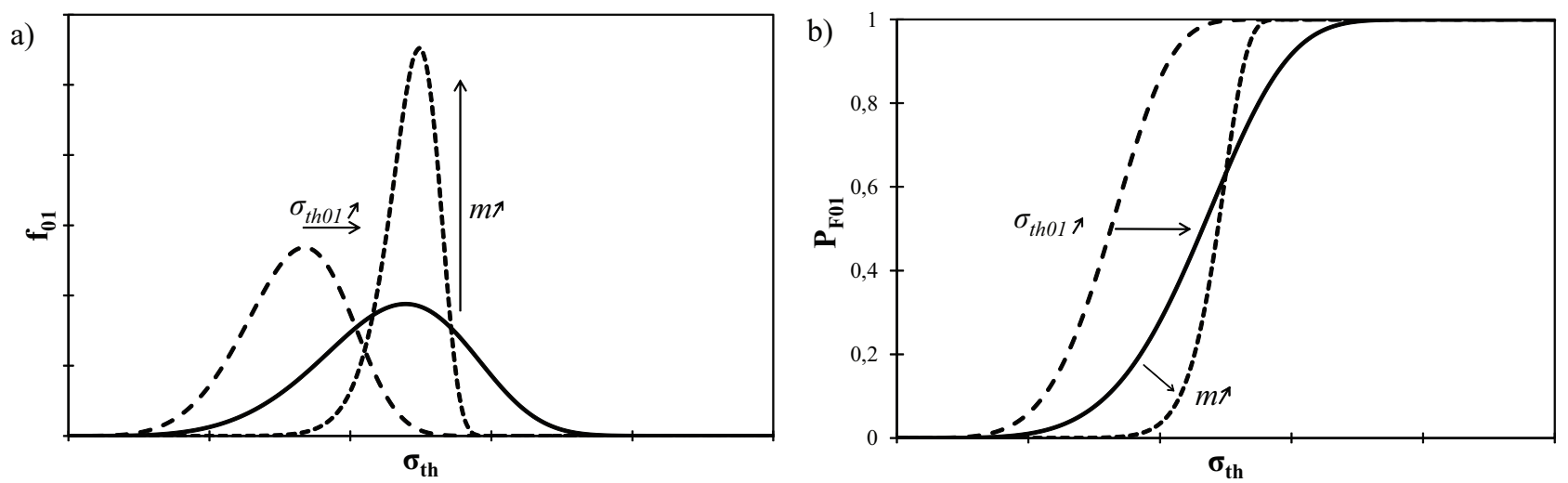

Fig. 2: Effect of the exponent $m_{1}$ and the scale factor $\sigma_{t h 01}$ on the a)Probability density function b)the cumulative distribution function

To obtain the probability of crack initiation for the complete structure $P_{F_{1}}$, the weakest link theory is used [22]. The probability of survival of the structure $\left(1-P_{F_{1}}\right)$ is defined as the product of the survival probabilities of each elementary volume or surface. In this work it will be assumed that crack initiation is essentially a surface phenomenon, where the quantity $S_{01}$ corresponds to the surface area of an individual surface grain and $S_{\Omega 1}$ is the total surface area of a specimen. Hence the probability of survival of the complete structure is given by:

$$
1-P_{F_{1}}=\prod_{S_{\Omega 1}}\left(1-P_{F_{01}}(M)\right)
$$

This then implies that:

$$
P_{F_{1}}=1-\exp \left[-\frac{1}{S_{01}} \int_{S_{\Omega 1}}\left(\frac{\sigma_{e q}}{\sigma_{t h 01}}\right)^{m_{1}} d S\right]
$$

For a uniform surface stress, this expression can be simplified to: 


$$
P_{F_{1}}=1-\exp \left[-\frac{S_{\Omega 1}}{S_{01}}\left(\frac{\sigma_{e q}}{\sigma_{t h 01}}\right)^{m_{1}}\right]
$$

\subsection{Probabilistic modelling of damage mechanism 2}

This section is devoted to the modelling of the second fatigue damage mechanism associated with the non-propagation (or the arrest) of long cracks. The classical LEFM approach to fatigue will be used to demonstrate the modelling framework. Although it should be kept in mind that the framework is not limited to LEFM. Any criterion that predicts the fatigue behaviour of long cracks or defects could be used (e.g. Elastic-Plastic Fracture Mechanics or the Murakami criterion [4]).

When using the classical LEFM approach to predict fatigue behaviour it is assumed that crack propagation does not occur if the following condition is satisfied:

$$
\Delta K<\Delta K_{t h}
$$

That is, a crack will not propagate under cyclic loading if its stress intensity range, $\Delta K$, is less than the crack propagation threshold, $\Delta K_{t h}$. As before, the inherent stochastic character of the propagation threshold will be modelled using a second Weibull distribution [20, 21] for which the probability density function is given by:

$$
f_{02}\left(\Delta K_{t h}\right)=\frac{m_{2}}{\Delta K_{t h 02}}\left(\frac{\Delta K_{t h}}{\Delta K_{t h 02}}\right)^{m_{2}-1} \exp -\left(\frac{\Delta K_{t h}}{\Delta K_{t h 02}}\right)^{m_{2}}
$$

In this case the shape factor or the Weibull exponent, $m_{2}$, governs the scatter and $\Delta K_{t h 02}$ is the scale factor of this distribution (associated with damage mechanism 2).

The probability of a crack propagating, corresponds to the probability that $\Delta K_{t h}$ is inferior to $\Delta K$ :

$$
P_{F_{02}}=\left(\Delta K_{t h}<\Delta K\right)=\int_{0}^{\Delta K} f_{02}\left(\Delta K_{t h}\right) d \Delta K_{t h}
$$

The failure probability calculated for one crack is therefore:

$$
P_{F_{02}}=1-\exp \left[-\left(\frac{\Delta K}{\Delta K_{t h 02}}\right)^{m_{2}}\right]
$$


As before, if it is assumed that fatigue is essentially a surface phenomenon, the quantity $S_{02}$ corresponds to the surface area associated with one fatigue crack and $S_{\Omega 2}$ is the total surface area of a specimen. Hence, the probability of survival of the total structure is given by:

$$
P_{F_{2}}=1-\exp \left[-\frac{1}{S_{02}} \int_{S_{\Omega 2}}\left(\frac{\Delta K}{\Delta K_{t h 02}}\right)^{m_{2}} d S\right]
$$

For a uniform stress, this expression can be simplified to:

$$
P_{F_{2}}=1-\exp \left[-\frac{S_{\Omega 2}}{S_{02}}\left(\frac{\Delta K}{\Delta K_{t h 02}}\right)^{m_{2}}\right]
$$

\subsection{Combining the two damage mechanisms}

Finally, the survival probability of an entire component, due to both damage mechanisms, is equal to the product of the two survival probabilities (see Equation 14). Essentially, the weakest link hypothesis [22], is employed once again, which assumes that the two damage mechanisms are independent.

$$
1-P_{F}=\left(1-P_{F_{1}}\right)\left(1-P_{F_{2}}\right)
$$

For a uniform surface stress, the total probability of failure can be written as:

$$
P_{F}=1-\exp \left\{-\left[\frac{S_{\Omega 1}}{S_{01}}\left(\frac{\sigma_{e q}}{\sigma_{t h 01}}\right)^{m_{1}}+\frac{S_{\Omega 2}}{S_{02}}\left(\frac{\Delta K}{\Delta K_{t h 02}}\right)^{m_{2}}\right]\right\}
$$

This is simply a bimodal Weibull model. As can be seen in equation 15 the scale effect is explicitly taken into account via the terms $\frac{S_{\Omega 1}}{S_{01}}$ and $\frac{S_{\Omega 2}}{S_{02}}$. In the following, for reasons of simplicity, the scale effect will be neglected, which corresponds to the assumption that the results presented below are for specimens with approximately the same surface area. Equation 15 can therefore be simplified to:

$$
P_{F}=1-\exp \left\{-\left[\left(\frac{\sigma_{e q}}{\sigma_{t h 01}^{\prime}}\right)^{m_{1}}+\left(\frac{\Delta K}{\Delta K_{t h 02}^{\prime}}\right)^{m_{2}}\right]\right\}
$$

Where

$$
\sigma_{t h 01}^{\prime}=\sigma_{t h 01}\left(\frac{S_{01}}{S_{\Omega 1}}\right)^{1 / m_{1}} \quad \text { and } \quad \Delta K_{t h 02}^{\prime}=\Delta K_{t h 02}\left(\frac{S_{02}}{S_{\Omega 2}}\right)^{1 / m_{2}}
$$




\section{A unified fatigue criterion and a probabilistic Kitagawa-Takahashi diagram}

\subsection{For uniaxial fully reversed tension-compression loads}

In this section fully reversed uniaxial push-pull loads are investigated in conjunction with the same criteria as those used in the original Kitagawa-Takahashi diagram to illustrate the possibilities of this modelling framework. Consequently, a probabilistic uniaxial Kitagawa-Takahashi diagram is generated.

The two criteria chosen are (a) the simple stress amplitude criterion and (b) the LEFM criterion, for which it is assumed that the opening mode (Mode I) is the dominate crack propagation driving force. These criteria are described by the following equations:

$$
\sigma_{e q}=\sigma_{I, a} \geqslant s_{-1} \quad \text { and } \quad \Delta K=Y 2 \sigma_{I, a} \sqrt{\pi a} \geqslant \Delta K_{t h}
$$

Where $Y$ is the crack shape correction factor, $a$ is the crack size and $2 \sigma_{I, a}=\Delta \sigma_{I}$. Note that Equations 18 are valid for a fixed R-ratio and crack geometry.

In first approximation, crack closure has been neglected in this paper. For the sake of simplicity it will be assumed that the two damage mechanisms are characterised by the same degree of scatter. This is equivalent to assuming that the Weibull shape parameters are the same (or $m=m_{1}=m_{2}$ ). By substituting equations 18 into equation 16 the following expression for the fatigue strength as a function of the probability of failure, and the crack length, can be established:

$$
\sigma_{I, a}\left(P_{F}, a\right)=\left[\frac{\ln \left(\frac{1}{1-P_{F}}\right)}{\left(\frac{1}{\sigma_{t h 01}^{\prime}}\right)^{m}+\left(\frac{Y 2 \sqrt{\pi a}}{\Delta K_{t h 02}^{\prime}}\right)^{m}}\right]^{\frac{1}{m}}
$$

Note that the fatigue life, for which $P_{F}=0.5$ is given by:

$$
\sigma_{I, a}\left(P_{F}=0.5, a\right)=\left[\frac{\ln (2)}{\left(\frac{1}{\sigma_{t h 01}^{\prime}}\right)^{m}+\left(\frac{Y 2 \sqrt{\pi a}}{\Delta K_{t h 02}^{\prime}}\right)^{m}}\right]^{\frac{1}{m}}
$$


Equation 19, plotted as a function of the crack size, $a$, for a given probability of failure, results in a probabilistic Kitagawa-Takahashi diagram. This diagram can be used to predict the fatigue strength of a material with and without the presence of cracks (see Figure 3(a) and (b)). As previously discussed the diagram can be divided into three zones:

- Zone 1: When the crack length is small, the fatigue strength is controlled by the initiation damage mechanism. Mathematically, the term $\left(\frac{Y 2 \sqrt{\pi a}}{\Delta K_{t h 02}^{\prime}}\right)^{m}$ in the dominator of equation 19 represents mechanism 2 and is much smaller than the term $\left(\frac{1}{\sigma_{t h 01}^{\prime}}\right)^{m}$ defining mechanism 1.

- Zone 2: is a transition zone in which $\left(\frac{Y 2 \sqrt{\pi a}}{\Delta K_{t h 02}^{\prime}}\right)^{m} \approx\left(\frac{1}{\sigma_{t h 01}^{\prime}}\right)^{m}$. This implies that both damage mechanism are active.

- Zone 3: When crack is large $\left(\frac{Y 2 \sqrt{\pi a}}{\Delta K_{t h 02}^{\prime}}\right)^{m} \gg\left(\frac{1}{\sigma_{t h 01}^{\prime}}\right)^{m}$. Which implies that damage mechanism 2 is dominate.

It is very important to understand that, even though LEFM is one of the ingredients used to generate the Kitagawa-Takahashi diagram, the short crack problem is intrinsically taken into account via the use of the modelling framework, which combines the two fatigue damage mechanisms. When the crack or defect size is small, the dominate fatigue damage is due to localised cyclic plasticity (i.e. mechanism 1) and the contribution from the LEFM part of the model becomes negligible.

Also with this modelling framework it is possible to predict the fatigue strength for different probabilities of failure.

Note that the shape of the curve in the transition zone is strongly dependent on the Weibull exponent or the shape parameter $m$ (see Figure 4). This implies that the scatter associated with the fatigue strength greatly affects the transition between the two damage mechanisms. When the scatter increases (i.e. $m$ decrease) the size of the transition zone also increases. Conversely, when the scatter is negligible (i.e. $m$ tends to infinity) the transition zone is effectively eliminated and the diagram becomes equivalent to the original Kitagawa-Takahashi diagram with only two lines. 


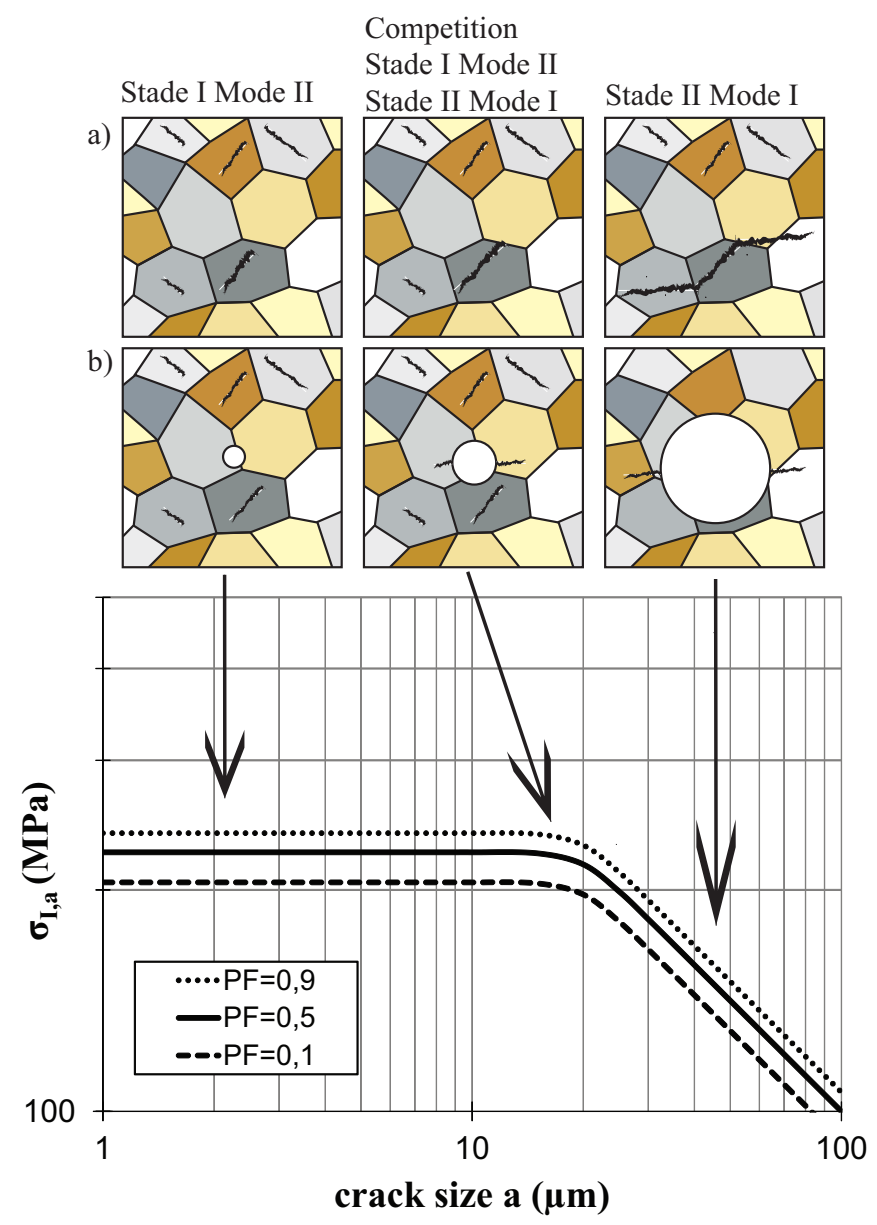

Fig. 3: Kitagawa-Takahashi diagram, corresponding to Equation 19, for difference failure probabilities showing the fatigue damage mechanisms a) without and b) with initial defects for the three zones of the diagram. For uniaxial push-pull loads $\left(m=20, \sigma_{t h 01}^{\prime}=234 M P a, Y=2 / \pi, \Delta K_{t h 02}^{\prime}=2.3 M P a . m^{1 / 2}\right)$

\subsection{Comparison with the El Haddad approach}

One of the original solutions to the LEFM short crack problem was proposed by El Haddad [9], who introduced the material constant, $a_{o}$, such that fatigue strength of a cracked body (and the Kitagawa-Takahashi diagram) could be described by:

$$
2 \sigma_{1, a}=\frac{\Delta K_{t h}}{Y \sqrt{\pi\left(a+a_{o}\right)}} \quad \text { where } \quad a_{o}=\frac{1}{\pi}\left(\frac{\Delta K_{t h}}{2 s_{-1}}\right)^{2}
$$

It can be demonstrated mathematically that the El Haddad approach is in fact a specific case of the proposed probabilistic modelling framework defined by Equation 19 for a uniaxial loading 


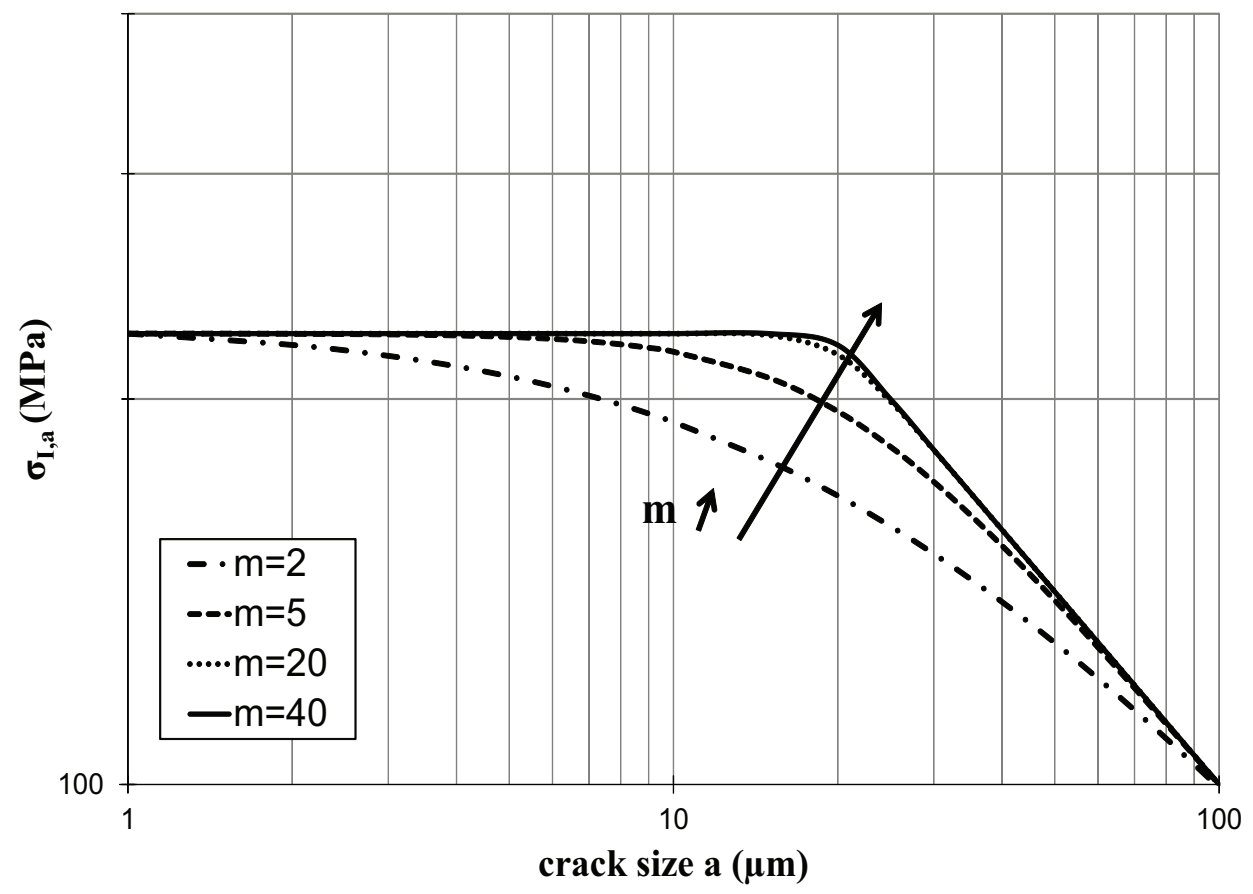

Fig. 4: Kitagawa-Takahashi diagram, corresponding to Equation 19 for different Weibull exponents $m$ and for a probability of failure of $P_{F}=0.5$

condition. The El Haddad equation corresponds to an Weibull exponent of $m=2$ and a probability of failure of $P_{F}=0.544$. The exact correspondence is given by:

$$
2 \sigma_{I, a}(0.544, a)=\frac{\ln \left(\frac{1}{1-0.544}\right)}{Y \sqrt{\pi \frac{a+a_{0}}{\Delta K_{t h 02}^{\prime}}}}=\frac{\Delta K_{t h}}{Y \sqrt{\pi\left(a+a_{o}\right)}}
$$

Figure 5, demonstrates the correspondence between the two approaches for a specific set of data.

\subsection{Extension to multiaxial loads}

In order to apply the proposed modelling framework to multiaxial loading conditions, the Crossland criterion [17] is chosen to model the first damage mechanism associated with crack 


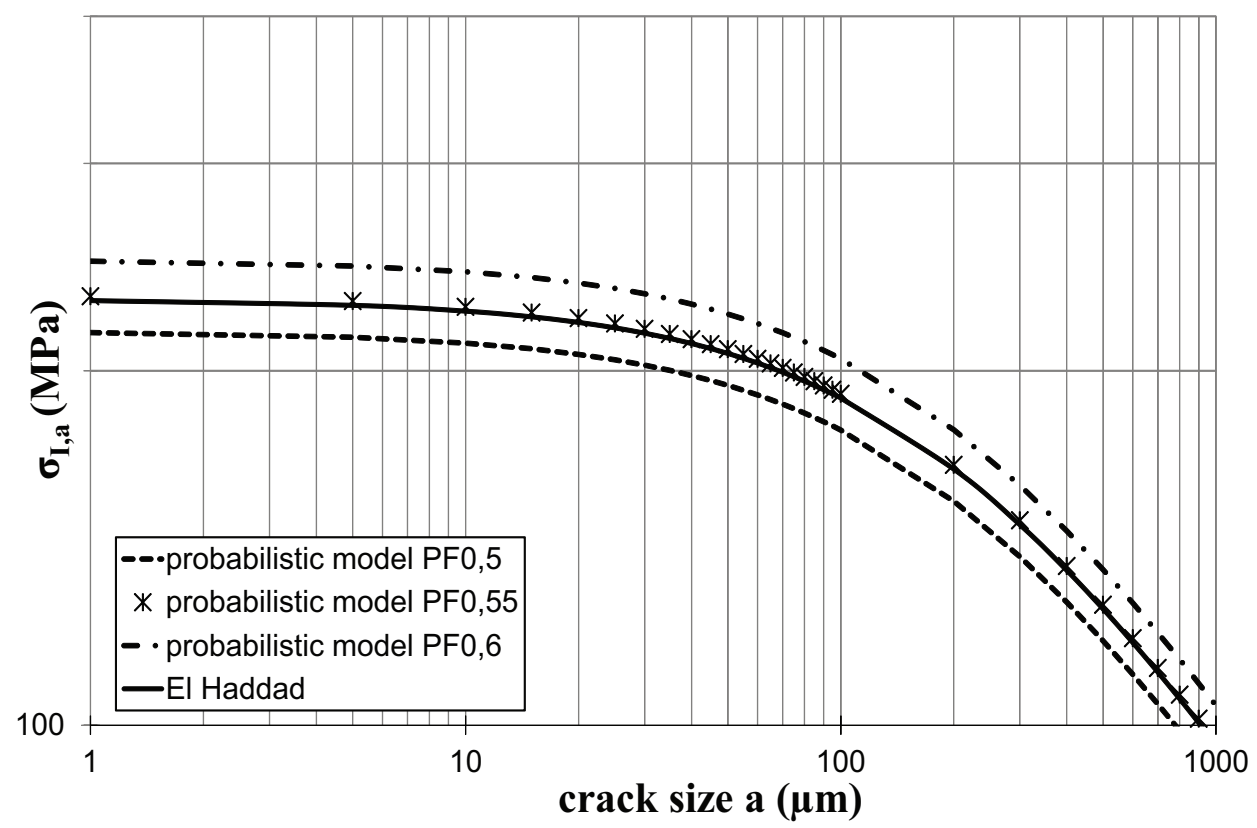

Fig. 5: Kitagawa-Takahashi diagram: comparison between the El Haddad approach and the proposed probabilistic model for uniaxial push-pull loads $\left(\Delta K_{t h}=11.9 \mathrm{MPa} . \mathrm{m}^{1 / 2}, S_{-1}=230 \mathrm{MPa}, \mathrm{m}=2.0, \sigma_{t h 01}^{\prime}=260 \mathrm{MPa}, \mathrm{Y}=\right.$ 1.0, $\left.\Delta K_{t h 02}^{\prime}=13.4 M P a . m^{1 / 2}\right)$

initiation. The equivalent and threshold stresses are given in Table 1, For the sake of simplicity it will be assumed that even under a multiaxial loading condition the most damaging long crack opening mode is mode I and that the LEFM criterion discussed above will again be used to model the second damage mechanism.

In the following three different loading conditions are investigated. These are: (a) fully reversed uniaxial push-pull loads (b) fully reversed torsion, and (c) combined in-phase synchronous tension-torsion with $\tau / \sigma=1$. Table 2 summarises the application of the proposed modelling framework for these loading conditions.

\section{Numerical application using experimental data for the C35 steel}

\subsection{The material}

In this section the proposed fatigue model, summarised in Table 2, will be applied to the C35 steel. This material is a ferrito-perlitic, low alloy steel containing $0.35 \%$ carbon that is used for 


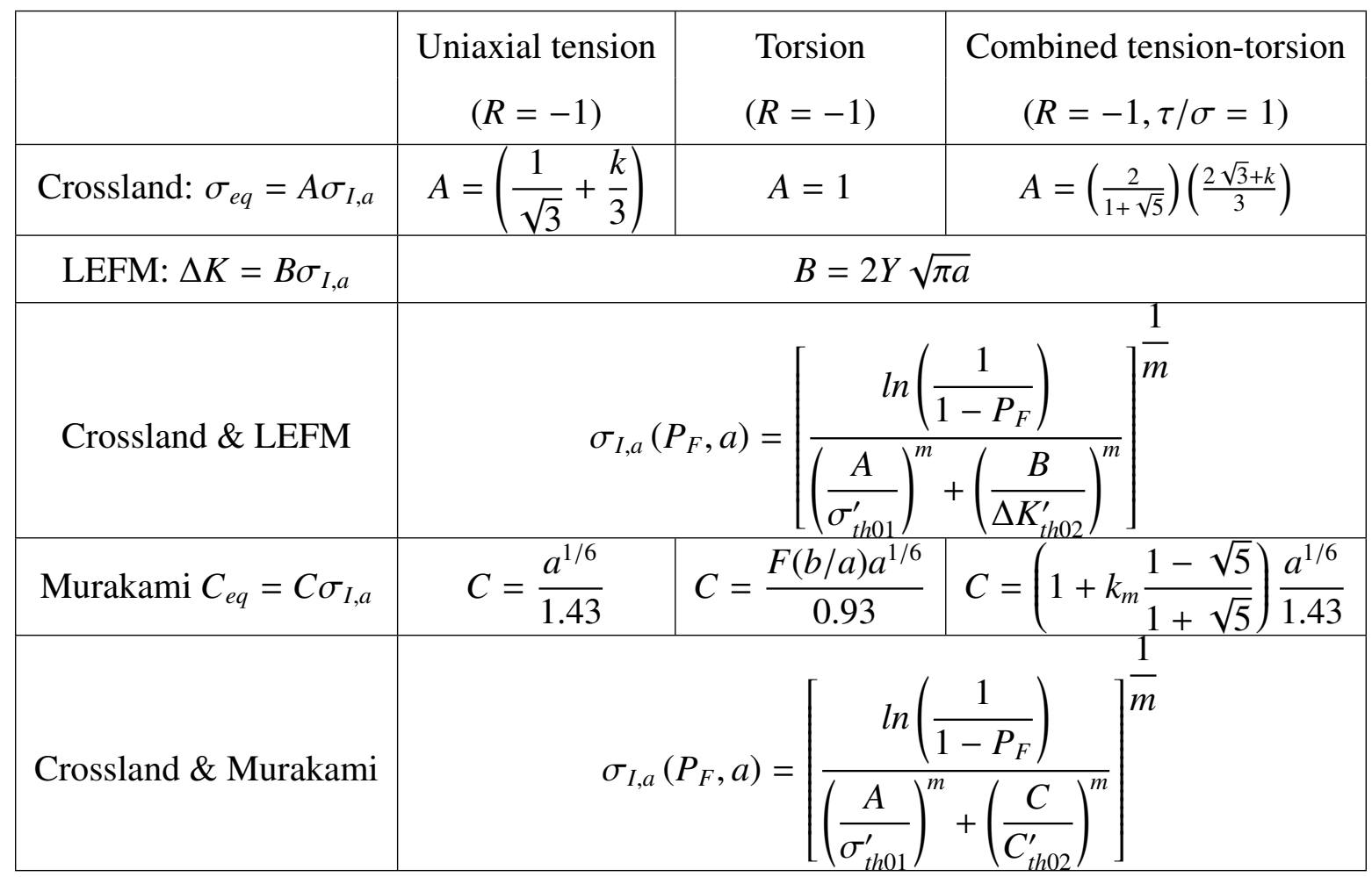

Table 2: Application for the proposed modelling framework, using the Crossland \& LEFM criteria combination and the Crossland \& Murakami criteria combination, for three different loading conditions

many structural applications. A great number of fatigue data have been reported in the literature for this material [10, 23, 24, 25, 26]. In particular, Flaceliere [25] and Morel [26] studied the fatigue behaviour of this material using plain specimens (without the presence of pre-existing cracks or defects). Whereas McEvily [10], Billadeau [23] and Nadot [24] have investigated the influence of artificial surface defects on the fatigue resistance, when subject to different loading conditions (uniaxial push-pull loads, fully reversed torsion and combined tension-torsion).

Table 3 summarises the experimental fatigue data taken from the literature for this material. Data for both plain specimens (defect size $=0 \mu \mathrm{m}$ ) and specimens containing artificial hemispherical surface defects of various sizes are reported for three different loading conditions. The data in Bold is used below to identify the parameters of the proposed modelling framework. 


\begin{tabular}{|c|c|c|c|}
\hline $\begin{array}{l}\text { Defect size } \\
\qquad(\mu m)\end{array}$ & $\begin{array}{l}\text { Tension } \\
s_{-1}(\mathrm{MPa})\end{array}$ & $\begin{array}{c}\text { Torsion } \\
t_{-1}(\mathrm{MPa})\end{array}$ & $\begin{array}{c}\text { Tension-Torsion } \\
s t_{-1}(\mathrm{MPa})\end{array}$ \\
\hline 0 & 230 & 140 & 185 \\
\hline 90 & 200 & 140 & 175 \\
\hline 500 & 150 & 120 & - \\
\hline
\end{tabular}

Table 3: The fully reversed $(\mathrm{R}=-1)$ fatigue strength at $1 \times 10^{7}$ cycles for different loading conditions and defect sizes (i.e. artificial hemispherical surface defects)

\subsection{The identification procedure}

The previously presented model, using the Crossland \& LEFM criteria includes five model parameters $\left(\Sigma_{t h 01}^{\prime}, k, \Delta K_{t h 02}^{\prime}, m_{1}, m_{2}\right)$, which can be reduced to four parameters if it is assumed that $m=m_{1}=m_{2}$. In the following section the method of identifying these parameters is presented.

\subsubsection{The parameters $m_{1}, m_{2}$ or $m$}

For the C35 steel only the scatter associated with the plain specimen fatigue strength is known [23], in the form of the standard deviation of the Gaussian distribution associated with the fatigue strength at $1 \times 10^{7}$ of cycles. Hence, in the following it will be assumed that the scatter associated with the second damage mechanism is equivalent to that of the first mechanism (or that $m_{1}=m_{2}=$ m).

This assumption is made out of necessity, due to the fact that the dispersion associated with the second mechanism is not reported in the literature. However, it has been observed that for other metallic materials the parameters $m_{1}$ and $m_{2}$ can vary significantly. For example, for the hot rolled steel, MetascoMC (25MnCrSiVB6), there is more scatter associated with the fatigue strength of the material without defects than when defects are present $\left(m_{1}=30\right.$ and, $\left.m_{2}=48\right)$ [14, 15, 16]. For this material the defects were found in the form of clusters of elongated MnS inclusions.

In general, the parameter $m$ associated with the scatter in the fatigue strength can be calculated from the standard deviation, $\overline{\bar{S}}_{-1}$, and the average fatigue strength, $\bar{s}_{-1}$, using the following relationship. 


$$
\frac{\overline{\bar{s}}_{-1}}{\overline{\bar{s}}_{-1}}=\frac{\sqrt{\Gamma\left(1+\frac{2}{m}\right)-\Gamma^{2}\left(1+\frac{1}{m}\right)}}{\Gamma\left(1+\frac{1}{m}\right)}
$$

Where $\Gamma(t)=\int_{0}^{\infty} x^{t-1} e^{-x}$ is the gamma function [27]. The same approach could be used to determine the parameter $m_{2}$ associated with the scatter in the fatigue crack propagation threshold, $\Delta K_{t h}$ if the mean value and standard deviation were known.

\subsubsection{The parameters $\sigma_{\text {th } 01}^{\prime}$ and $k$}

It should be remembered that for this example the Crossland criterion [17] is chosen to model the first damage mechanism. The parameters $\sigma_{t h 01}$ and $k$ are associated with this Criterion and damage mechanism.

The parameter $\sigma_{t h 01}^{\prime}$ is the scale parameter of the Weibull distribution governing the first damage mechanism and can therefore be thought of as being a material constant. For a a given material this constant can be determined from the torsional fatigue strength $t_{-1}$ of the material, using the equation:

$$
t_{-1}=\sigma_{t h 01}^{\prime} \Gamma\left(1+\frac{1}{m_{1}}\right)
$$

Once the parameter $\sigma_{t h 01}^{\prime}$ is known, the plain specimen uniaxial fatigue strength, $s_{-1}$, can be used to determine the parameter, $k$ (or the Crossland parameter used to defines the sensitivity to the hydrostatic stress). For this, Equation 25 can be used.

$$
s_{-1}=\frac{3 \sigma_{t h 01}}{\sqrt{3}+k} \Gamma\left(1+\frac{1}{m}\right)
$$

\subsubsection{The parameters $\Delta K_{t h 02}^{\prime}$}

The final parameter that must be identified is $\Delta K_{t h 02}^{\prime}$ and is associated with the second fatigue damage mechanism, modelled using the LEFM criteria. This material constant is the scale parameter associated with the Weibull distribution defining the long crack propagation threshold and can be identified in one of two ways:

- by experimentally determining the average long crack fatigue propagation threshold. 
- by experimentally determining the fatigue strength of the material for a known crack or defect size $s_{a_{i}}^{-1}$, which is large enough so that the second damage mechanism is dominate.

For the first case Equation 26 can be used.

$$
S_{a_{i}}^{-1}=\frac{\Delta K_{t h 02}^{\prime}}{2 Y \sqrt{\pi a}} \Gamma\left(1+\frac{1}{m}\right)=\frac{\Delta K_{t h}}{2 Y \sqrt{\pi a}}
$$

\subsubsection{Parameters identified for the C35 steel}

Table 4 summarizes the four model parameters identified for the $\mathrm{C} 35$ steel, using the fatigue data and identification procedure outlined above.

\begin{tabular}{lll} 
Model Parameters & & \\
\hline scatter parameter & $m$ & 24 \\
Crossland & $\sigma_{t h 01}^{\prime}$ & $143.2 \mathrm{MPa}$ \\
& $k$ & 0.09 \\
LEFM & $\Delta K_{t h 02}^{\prime}$ & $7.7 \mathrm{MPa} \sqrt{m}$ \\
Murakami & $C_{t h 02}^{\prime}$ & 302 \\
\hline
\end{tabular}

Table 4: Model parameters identified for the C35 steel using the Crossland and LEFM or Crossland and Murakami criteria to model the two damage mechanisms $\left(N=1 \times 10^{7}\right.$ cycles, $\left.R=-1\right)$

The parameter $m$ has been determined using Equation 23 by assuming that the standard deviation associated with the uniaxial fatigue strength is $12 \mathrm{MPa}[23]$.

\subsection{Application using the Crossland $\mathcal{E}$ LEFM criteria combination}

Figure 6 shows the predictions of the proposed modelling framework using the equations for the Crossland \& LEFM criteria combination (see Table 2). The experimental data listed in Table 3 is also shown.

It can be seen that in the short crack zone of the diagram the Crossland criterion faithfully predicts the results for the combined tension-torsion loading condition. However, in the long crack domain, it appears that the LEFM criterion overestimates the fatigue strength.

The difference between the experimental and predicted results, seen in Figure 6, maybe due to the fact that the experimental results are for artificial surface defects with a hemispherical shape. 


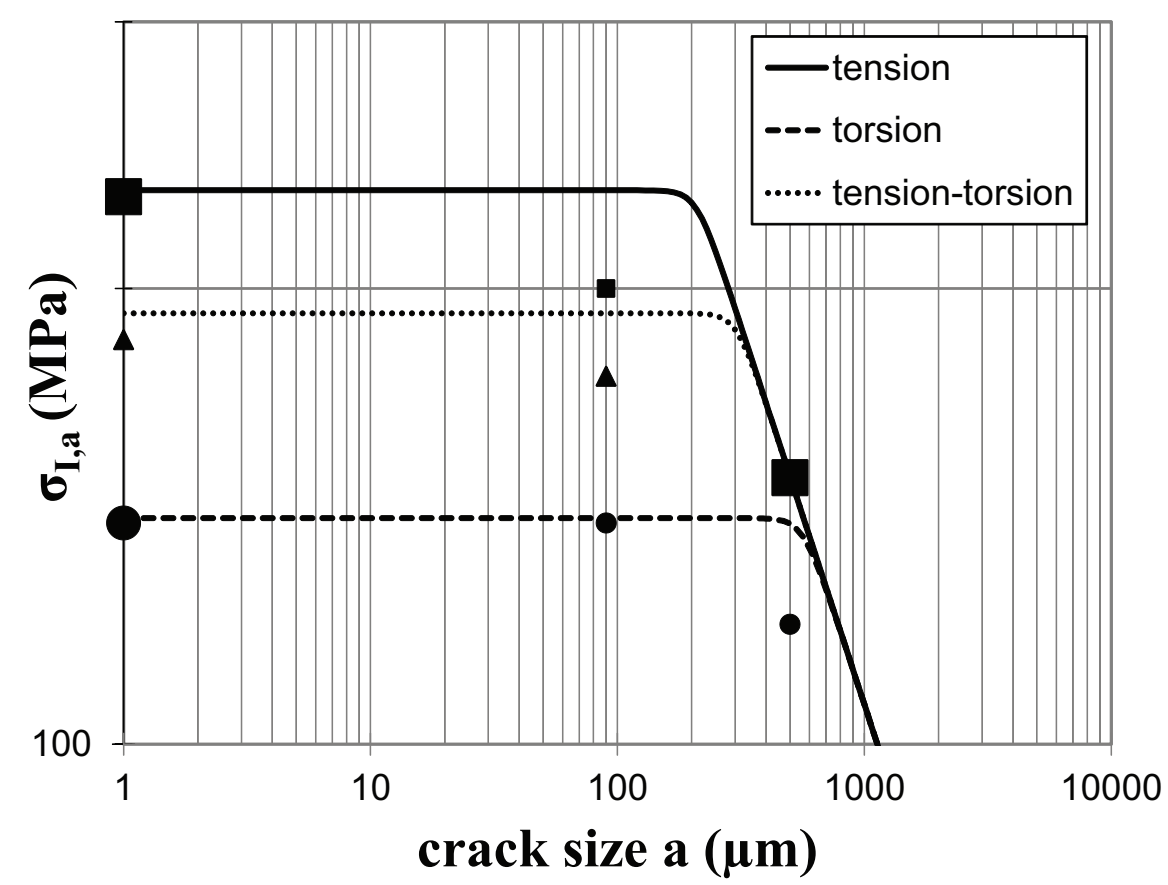

Fig. 6: Multiaxial Kitagawa-Takahashi type diagram established using the proposed modelling framework and the Crossland \& LEFM criteria combination, for the C35 steel, showing experimental data from the literature $\left(P_{F}=0.5\right)$, large data points are used for the identification of the model

The uses of the LEFM criterion in the modelling framework, makes the assumption that these defects are equivalent to cracks. In the following section an arguably more appropriate criterion for the prediction of the fatigue behaviour of defects will be applied to the same experimental data.

\subsection{Application using the Crossland $\mathcal{F}$ Murakami criteria combination}

In this section, the Murakami criterion [4] will be used to model the second damage mechanism associated with crack propagation. This empirical approach is well known for its ability to take into account the fatigue behaviour of artificial and natural defects of various sizes and shapes. In the following the Murakami criterion will be combined with the Crossland criterion and applied to the experimental data for the $\mathrm{C} 35$ steel presented above.

The Murakami criterion uses the parameter $\sqrt{\text { area }}$ (where area is the projected area of a defect on a plane perpendicular to the direction of the maximum principal stress) and the hardness 
to define the fatigue strength. For fully reversed push-pull loads, the following equation can be used to estimate the fatigue strength:

$$
\sigma_{w, a}=\frac{1.43\left(H_{v}+120\right)}{(\sqrt{\text { area }})^{1 / 6}}
$$

For hemispherical surface defects, the relationship between the crack length, $a$, and the parameter $\sqrt{\text { area }}$ is defined by Murakami [4] as: $a=2 \sqrt{2 / \pi} \sqrt{\text { area }}$. Hence, the non-failure condition, for fully reversed uniaxial push-pull loads, can be written as:

$$
\frac{\sigma_{I, a} a^{1 / 6}}{1.43}<\frac{H_{v}+120}{(2 \sqrt{2 / \pi})^{1 / 6}}
$$

Similarly, for fully reversed torsion loads, the survival condition can be written as:

$$
\frac{\tau_{w, a} F(b / a) a^{1 / 6}}{0.93}=\frac{\sigma_{I, a} F(b / a) a^{1 / 6}}{0.93}<\frac{H_{v}+120}{(2 \sqrt{2 / \pi})^{1 / 6}}
$$

Where $\mathrm{F}$ is a function of the defect aspect ratio $(b / a)$. For spherical defects $F(b / a)=0.8397$ [30].

For combined tension-torsion loads, the extension to the Murakami criterion, proposed by Endo and Ishimoto [28, 29], will be used. These authors consider that the fatigue strength for a fully reversed biaxial load can be determined from the uniaxial fatigue strength, such that:

$$
\sigma_{I, a}+k_{m} \sigma_{I I, a}=\sigma_{w, a}
$$

Where $k_{m}$ represent the effect of a biaxial stress state, determined by means of a stress analysis and is equal to $k_{m}=-0.18$ for a crack emanating from a round defect such as a hemispherical surface pit or a drilled hole [30].

The condition of non-failure for this type of loading condition can therefore be written as:

$$
\frac{\left(\sigma_{I, a}+k_{m} \sigma_{I I, a}\right) a^{1 / 6}}{1.43}<\frac{H_{v}+120}{(2 \sqrt{2 / \pi})^{1 / 6}}
$$

In order to simplify the notation, the following two constants will be used:

- $C_{e q}=\frac{\left(\sigma_{I, a}+k_{m} \sigma_{I I, a}\right) a^{1 / 6}}{1.43}$ represent the equivalent quantity used in the Murakami criterion 
- $C_{t h 02}=\frac{H_{v}+120}{(2 \sqrt{2 / \pi})^{1 / 6}}$ represents the threshold quantity with the Murakami criterion.

Using this notation, and following the same procedure outlined above, the expression for the probability of failure relating to the Murakami criterion (to model the second damage mechanism) can be expressed as:

$$
P_{F}=1-\exp \left\{-\left[\left(\frac{\sigma_{e q}}{\sigma_{t h 01}^{\prime}}\right)^{m_{1}}+\left(\frac{C_{e q}}{C_{t h 02}^{\prime}}\right)^{m_{2}}\right]\right\}
$$

Where $C_{t h 02}^{\prime}$ is the scale factor of the Weibull distribution used to model the scatter in the threshold quantity (taking into account the scale effect).

These equations are summarised in Table 2 .

Figure 7 shows the predictions obtained with the proposed modelling framework, using the Crossland \& Murakami criteria combination. It can be seen that the predictions, for all three loading conditions, are in very good agreement with the experimental data.

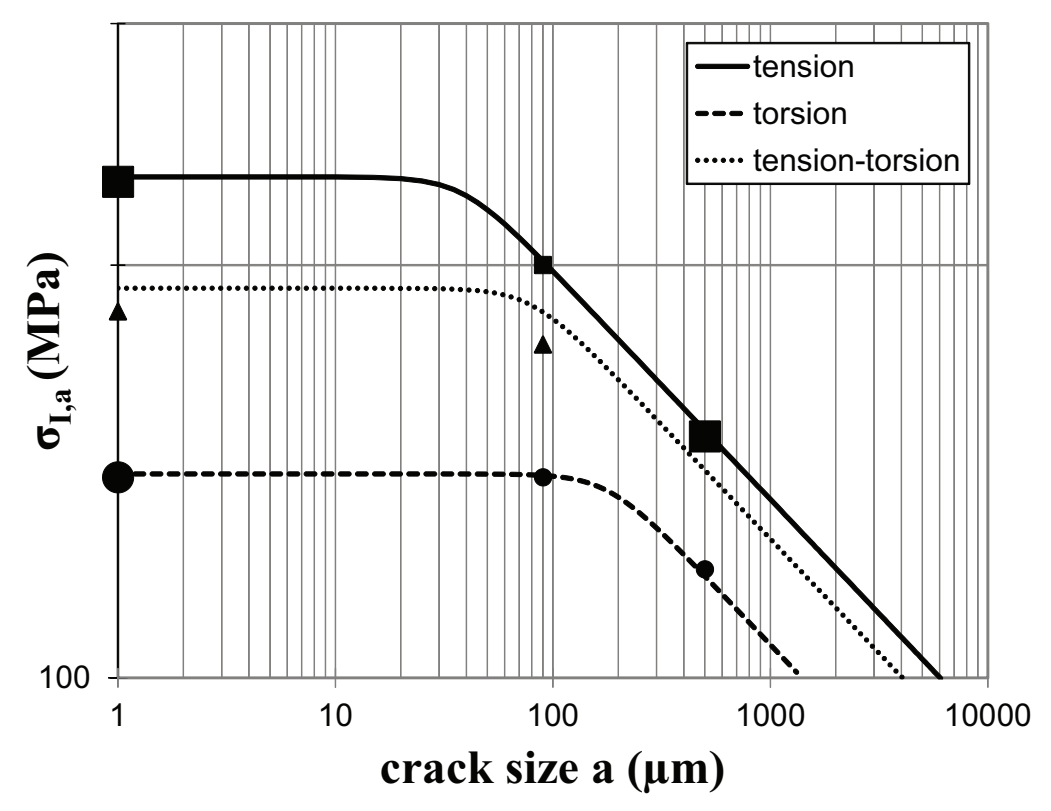

Fig. 7: Multiaxial Kitagawa-Takahashi type diagram established using the proposed modelling framework and the Crossland \& Murakami criteria combination, for the $\mathrm{C} 35$ steel, showing experimental data from the literature $\left(P_{F}=\right.$ $0.5)$, large data points are used for the identification of the model 


\section{Application to other materials}

In this section, two concrete applications of the proposed modelling framework are briefly presented. These involve the high cycle fatigue behaviour of two very different materials and engineering applications. Note that these applications are based on previous work done in the authors research group, and represent very specific applications of the proposed modelling framework, presented above in a more general form. This work is only briefly described below as it has been well documented elsewhere. [12, 13, 14, 15, 16]. As such, the objective of this section is to highlight the usefulness and flexibility of the proposed modelling framework.

\subsection{Forged bainitic steel - Metasco MC}

The modelling framework was originally proposed by Pessard et al. [14, 15, 16], in order to model the anisotropic fatigue behaviour of the hot rolled bainitic steel (Metasco MC) used in forging applications. For this material it was shown experimentally that two distinct fatigue damage mechanism can be activated. One damage mechanism involves crack initiation in the bainitic matrix of the material, and the other was due to cracks forming and propagating from clusters or bands of elongated Magnesium Sulphide inclusions. Figure 8 shows images taken on the surface of specimens, which illustrate these mechanisms.

Experimental observations showed that the difference in the fatigue behaviour for different material orientations (with respect to the rolling direction) was due to the activation (or not) of the second damage mechanism associated with the inclusion clusters.

In this work, the probabilistic modelling framework was used in combination with the Morel and Huyen [26] multiaxial fatigue criterion (to model mechanism 1) and the classical LEFM criterion, in which the inclusion clusters were assimilated to pre-existing cracks (to model mechanism 2). Figure 9 shows that this modelling approach is very successful in predicting the anisotropic fatigue behaviour of this material. 


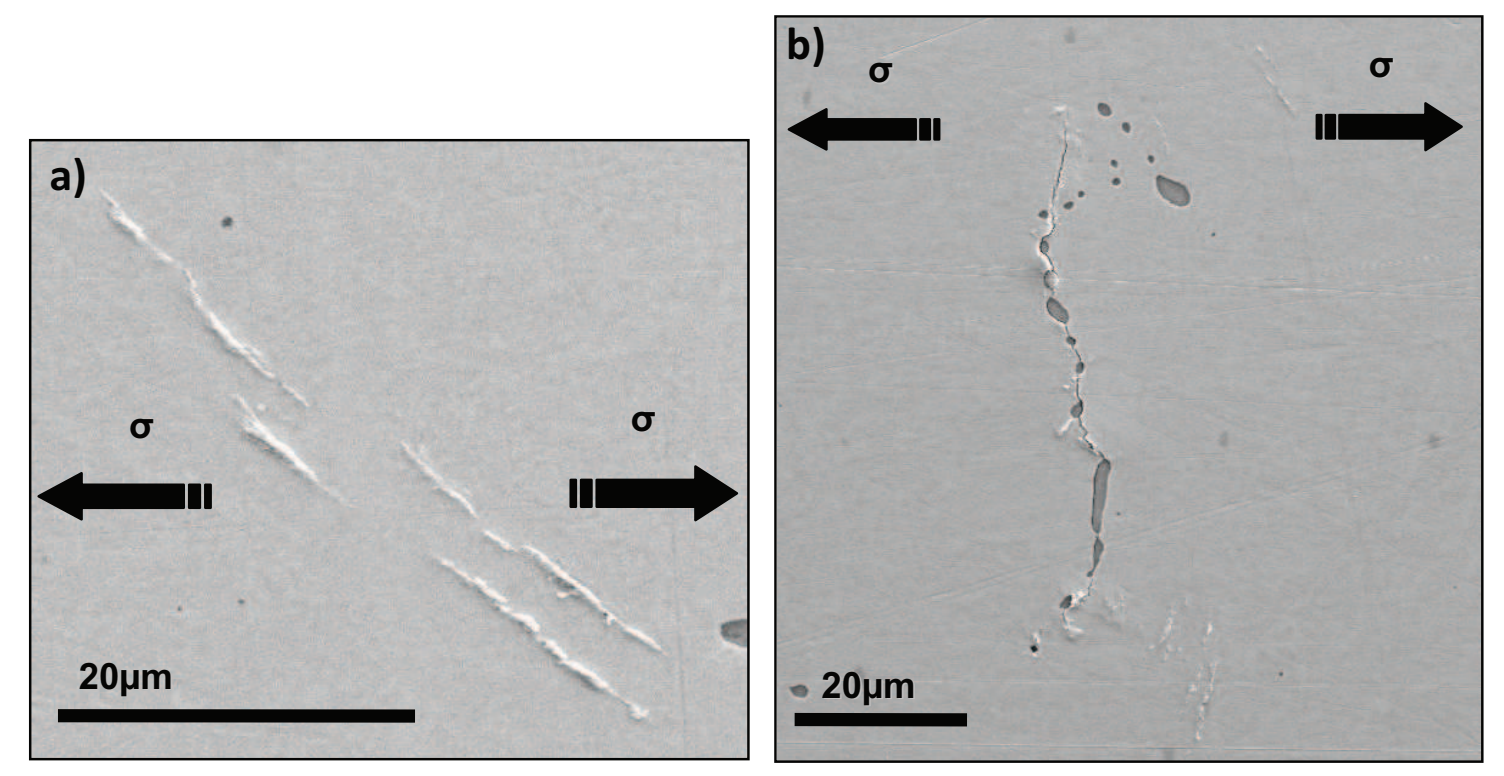

Fig. 8: Surface observations on fatigue specimens showing (a) the first fatigue damage mechanism: crack initiation due to meso-plasticity in slip bands at $45^{\circ}$ to the loading direction, (b) the second mechanism: crack occurring at a $\mathrm{MnS}$ inclusion cluster at $90^{\circ}$ to the loading direction

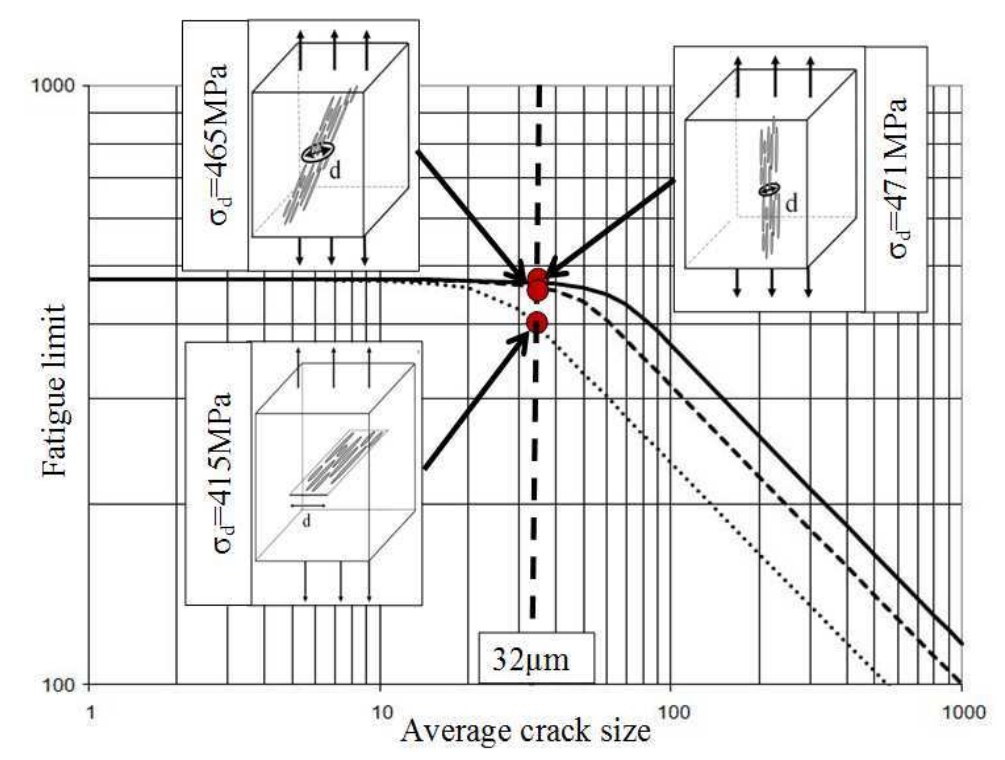

Fig. 9: Kitagawa-Takahashi diagram for the Metasco MC steel for fibering orientations of $0^{\circ}, 45^{\circ}$ and $90^{\circ}$ with respect to the loading direction [15] and comparison with experiential data points 


\subsection{Cast aluminium alloys}

The second application example concerns the high cycle fatigue behaviour of the AlSi7Cu05Mg03T7 cast aluminium alloy. Koutiri et al. [12, 13] showed experimentally, that for this material, two fatigue damage mechanism can also be identified. These are illustrated in Figure 10. The first mechanism is associated with crack initiation in the eutectic zones of the material and is assumed to be controlled by a micro-plasticity type mechanism. The second mechanism is associated with the propagation of cracks from micro-shrinkage pores.
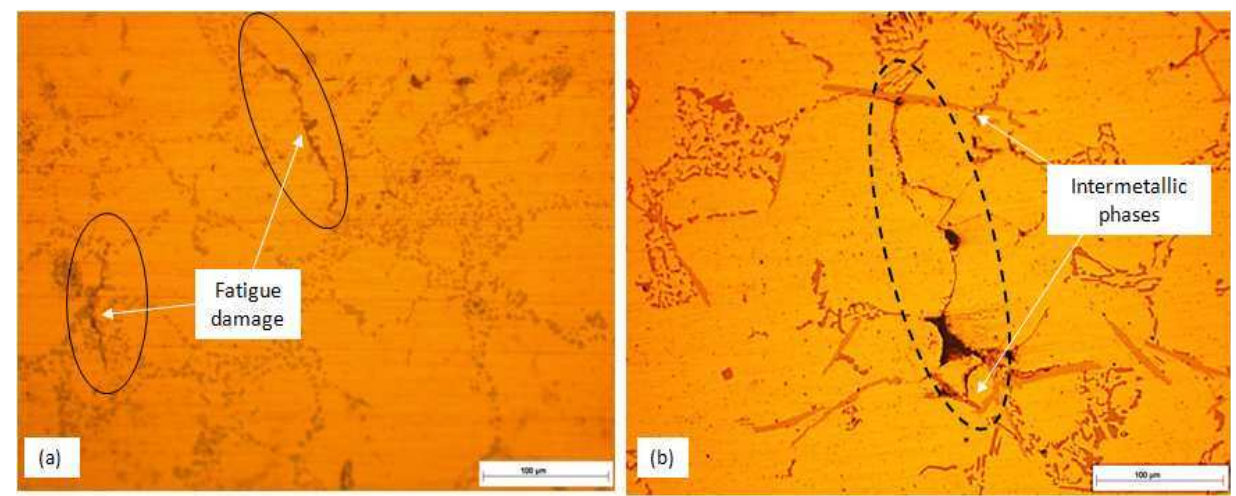

Fig. 10: Surface observations on fatigue specimens showing (a) the first fatigue damage mechanism involving crack initiation at Silicon particles in the eutectic zones, (b) the second damage mechanism involving crack growth from a micro-shrinkage pore. Note that the presence of intermetallic phases acting as microstructural barriers to further crack propagation

The probabilistic modelling framework was used in combination with the Morel and Huyen [26] fatigue criterion (to model mechanism 1) and the classical LEFM criterion, modified to take into account the mean stress effect, for the second damage mechanism concerning the propagation of cracks from micro-shrinkage pores. This modification was base on a Klesnil and Lucas [31] type correction so that the crack propagation threshold becomes a function of the load ratio.

For this material the proposed modelling framework, takes into account both of these damage mechanisms, and models the state of competition between them. This leads to a probabilistic Kitagawa-Takahashi type diagram (see Figure 11), which in this case explains the relationship between the fatigue behaviour of the material and the different casting processes or post-casting 


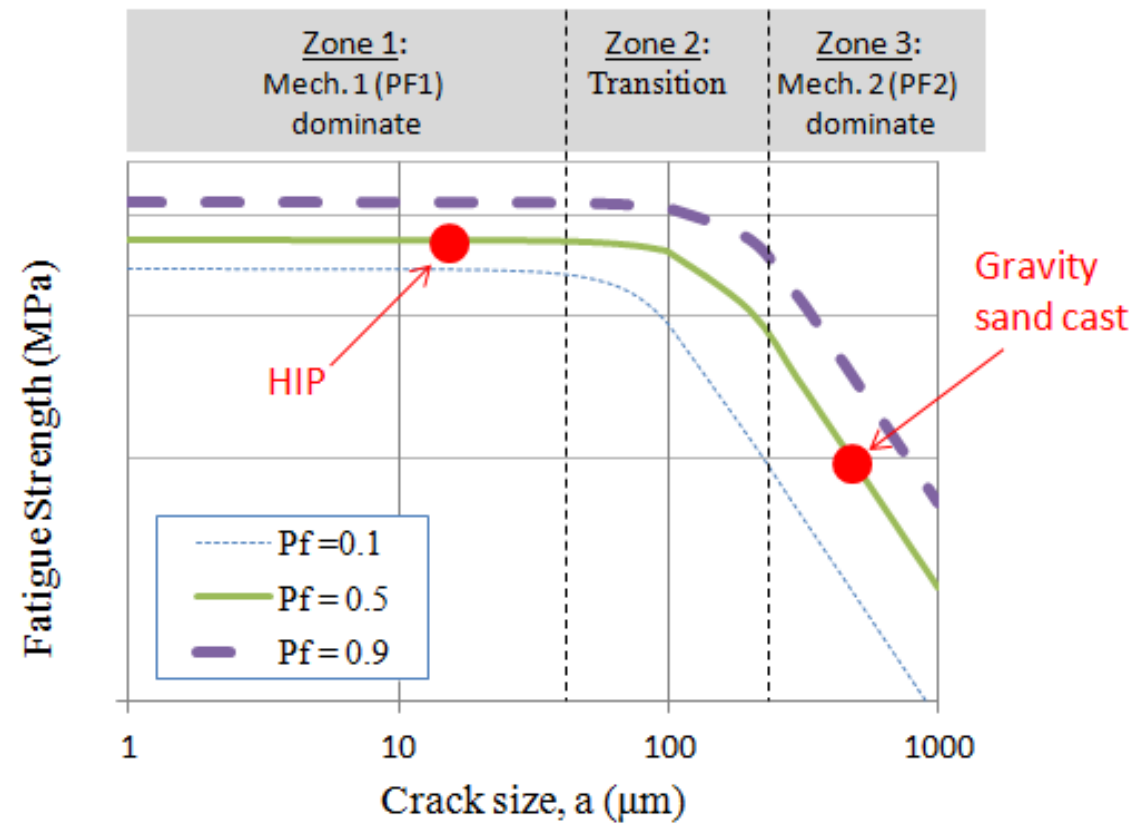

Fig. 11: Probablisitic Kitagawa-Takahashi diagram for the AlSi7Cu05Mg03-T7 cast aluminium alloy [13], schematically showing the effect of the HIP treatment

treatments. For example, a gravity cast components typically has a micro-shrinkage pore population characterised by large pore sizes. The presence of large defects leads to the rapid activation and dominance of the second damage mechanism. This was the case for the gravity sand cast material investigated by Koutiri et al. [12, 13] for which it was found that the final failure was typically caused by fatigue cracks that originated from large micro-shrinkage pores. Conversely, for a very similar material treated by the HIP post-casting process, so that micro-shrinkage porosity is dramatically reduced, the fatigue strength is controlled by the first fatigue damage mechanism [32] (see Figure 11).

\section{Discussion}

Since, the original publication of the Kitagawa-Takahashi diagram in 1976 [8] many researchers have investigated the short crack problem and have proposed high cycle fatigue criteria capable of predicting the fatigue strength of materials containing both long and short fatigue cracks. Two notable examples are discussed below. 
It was shown in 1999 by Taylor [33] that the Theory of Critical Distances in which the fatigue strength is evaluated at a critical distance in front of a crack or notch, correctly predicts the behaviour of short cracks. Indeed the line method, advocated by Taylor in the publication cited above is strictly equivalent to the El Haddad approach. These critical distance methods are extremely attractive, due to their simplicity. However, the mechanistic basis for why they work is still missing, even if Taylor and his co-workers have made efforts to establish this fundamental link [34, 35].

Another recent approach that is successful in resolving the short crack problem was proposed by Thieulot-Laure et al.[36]. This model is based on the critical distortional energy in the crack tip region, calculated using a linear elastic fracture mechanics approach. In particular, the first non-singular term of the asymptotic development of the elastic stress field close to the crack tip, (i.e. the T-stress) is used. The approach takes into account the defect size distribution, defect orientations, shapes and positions for multiaxial loading. The authors have demonstrated that their prediction are close to those of the Dang Van criterion for very small cracks.

Even if these criteria result in correct predictions for the short crack problem, our experimental observations of fatigue damages mechanisms lead us to advocate the proposed modelling framework [12, 13, 14, 15, 16], which uses a probabilistic approach to explicitly take into account the change in damage mechanism, which is at the origin of the Kitagawa-Takahashi diagram and the short crack problem. Note also, that in this article the Crossland criterion has been used for sake of simplicity. More sophisticated criterion such as the Morel and Huyen criterion [26] can and have been used in this modelling framework. As such, it is very important to understand that the identification procedure and the results obtained strongly depend on the criteria chosen to model the two damage mechanisms.

The choice, to explicitly model multiple damage mechanisms, is also confirmed by the experimental observations of other researchers, in particular Endo and Ishimoto [29], who showed that for sufficiently small defect sizes, crack initiation does not necessarily occur from either natural or artificial defects. In practice, when small artificial defects are introduced at the surface of smooth specimens, cracks often initiate in areas outside the zone of influence of the defect. 


\section{Conclusion}

The principal conclusions of this work can be summarised as follows:

- The proposed modelling framework is a flexible way of taking into account multiple, coexisting, fatigue damage mechanisms via the combination of two appropriate high cycle fatigue criteria. One criteria to model crack initiation damage and a second for crack propagation (or crack arrest).

- The proposed modelling framework can be used to establish probabilistic Kitagawa-Takahashi type diagrams that have a mechanistic basis and are able to realistically reflect the experimentally observed scatter associated with the damage mechanisms.

- The proposed modelling framework, makes it possible to generate probabilistic KitagawaTakahashi type diagrams for multiaxial loading conditions, if appropriate multiaxial criteria are used.

- When the classical LEFM criterion is used in this framework the short crack problem is circumvented or avoided. It is assumed that short cracks fall into the transition region of the Kitagawa-Takahashi diagram. That is, a crack is initiated due to a plasticity based mechanism (mechanism 1) in an isolated grain. As the crack grows to be a micro-structurally short crack and then finally a long crack, there is a gradual change in the damage mechanism towards the crack propagation mechanism (mechanism 2). This gradual transition is reproduced by the proposed modelling framework. This means that the classical long crack propagation threshold can be used. When short cracks are considered (i.e. zones I and II of the Kitagawa-Takahashi diagram) the probability of failure due to the propagation damage mechanism becomes negligible and hence the contribution from the LEFM criterion is also negligible.

\section{References}

[1] I.V. Papadopoulos, Fatigue limit of metals under multiaxial stress conditions: the microscopic approach, ISEI/IE 2464/93, Commission of the European Communities Joint Research Center, 1993 
[2] D.L. Mc Dowell, K. Gall, M.F. Horstemeyer, J. Fan, Microstructure-based fatigue modeling of cast A356-T6 alloy, Eng Fract Mech, (2003), Vol. 70, pp. 49-80

[3] A. Fatemi, D. F. Socie, Critical plane approach to multiaxial fatigue damage including out-of-phase loading, Fatigue and Fracture of Engineering Materials and Structures, (1988), vol. 11-3, pp. 149-165

[4] Y. Murakami (2002) Metal Fatigue : effects of small defects and non-metallics inclusion. London Elsevier

[5] S. Suresh, R.O Ritchie, Geometric model for fatigue crack closure induced by fracture surface roughness, Metall. Trans. A, (1982), vol. 13A-N9, pp. 1627-1631

[6] S. Suresh, Fatigue of materials - Second edition, Cambridge University Press, Cambridge, 2004

[7] P.J.E. Forsyth, A two stage process of fatigue crack growth, In Crack Propagation: Proceedings of Cranfield Symposium, (1962), pp. 76-94, London: Her Majesty’s Stationery Office

[8] H. Kitagawa, S. Takahashi, Applicability of fracture mechanics to very small cracks. In: ASM Proceedings of 2nd international conference on mechanical behaviour of materials. Metalspark, Ohio; 1976, pp. 62731

[9] M.H. El Haddad , T.H. Topper, K.N. Smith, Prediction of non propagating cracks, Eng F Mech,(1979), vol. 11 , pp. 573-584

[10] A.J. McEvily,M. Endo, S. Ishihara, The inuence of biaxial stress on the fatigue behaviour of defect-containing steels. ICF11. 2005

[11] P. Lukäs, L. Kunz, B. Weiss, R. Stickler, Notch Size Effect in Fatigue, Fatigue Fract. ENgn Mater. Struct., (1989), Vol. 12 - 3, pp. 175-186

[12] I. Koutiri, D. Bellett, F. Morel, L. Augustins, J. Adrien, High cycle fatigue damage mechanisms in cast aluminium subject to complex loads, Int J Fatigue, Vol. 47, (2013), pp. 4457

[13] I. Koutiri, D. Bellett, F. Morel, E. Pessard, A probabilistic model for the high cycle fatigue behaviour of cast aluminium alloys subject to complex loads, Int J Fatigue, Vol. 47, (2013), pp. 137147

[14] E. Pessard, F. Morel, A. Morel, The anisotropic fatigue behavior of forged steel, Advanced Engineering Materials, (2009), Vol. 11, pp. 732-735

[15] E. Pessard, F. Morel, A. Morel, D. Bellett, Modelling the role of non-metallic inclusions on the anisotropic fatigue behaviour of forged steel, Int. J. Fatigue, (2011), Vol. 33-4, pp. 568-577

[16] E. Pessard, F. Morel, C. Verdu, L. Flaceliere, G. Baudry, Microstructural heterogeneities and fatigue anisotropy of forged steels, Materials Science and Engineering A, (2011), Vol. 529-1, pp. 289-299

[17] B. Crossland, Effect of large hydrostatic pressures on the torsionnal fatigue strength of an alloy steel, Int conf on Fatigue of Metals, (1956), London

[18] K. Dang Van, Sur la résistance á la fatigue des métaux, Sci Tech Armement, 1973, 47

[19] E. Charkaluk, A. Constantinescu, H. Matournam, K. Dang Van, Revisiting the Dang Van criterion, Procedia Engineering, (2009), vol 1-1, pp 143-146

[20] W. Weibull, A statistical theory of the strength of materials, Roy. Swed. Inst. Eng. Res., Report 151, 1939 
[21] W. Weibull, A statistical distribution function of wide applicability, ASME J Appl Mech, (1951), 18, pp. 293-297

[22] A.M. Freudenthal, in: H. Liebowitz (Eds.), Fracture vol 2, Academic Press, New York, 1968, pp. 591-619

[23] T. Billaudeau,Y. Nadot,G. Bezine, Multiaxial fatigue limit for defective materials: mechanisms and experiments, Acta Materialia, (2004), vol 52, pp. 3911-3920

[24] Y. Nadot, T. Billaudeau, Multiaxial fatigue limit criterion for defective materials, Engineering Fracture Mechanics, (2006), vol. 73-1 , pp. 112-133

[25] L. Flaceliere, F. Morel, A. Dragon Competition between mesoplasticity and damage under HCF Elasticity/damage shakedown concept,International Journal of Fatigue, (2007), vol. 29, pp. 2281-2297

[26] F. Morel and N. Huyen, Plasticity and damage heterogeneity in fatigue, Theoretical and Applied Fracture Mechanics, (2008), vol. 49-1, pp. 98-127

[27] M. Abramowitz, A. Stegun, Handbook of Mathematical Functions, Dover, New York, 1965.

[28] M. Endo,The multiaxial fatigue strength of specimens containing small defects. In: Carpinteri A, de Freitas M, Spagnoli A, editors. Biaxial/multiaxial fatigue and fracture ESIS publication, vol. 31. Elsevier, 2003, pp. 243-264

[29] M. Endo, I. Ishimoto, The fatigue strength of steels containing small holes under out-of-phase combined loading, Int J Fatigue (2006), vol. 28, pp. 592-597.

[30] S. Beretta, Y. Murakami, SIF and threshold for small cracks at small notches under torsion, Fatigue Fract Engng Mater Struct, (2000), vol. 23, pp. 97-104

[31] M. Klesnil, P. Lukas, Effect of stress cycle asymmetry on fatigue crack growth, Mater Sci Eng, (1972), Vol. 9, pp. 23140

[32] J. Fan, D.L. Mc Dowell, M.F. Horstemeyer, K. Gall, Cyclic plasticity at pores and inclusions in cast AlSi alloys, Eng Fract Mech, (2003), vol. 70, pp. 281-302

[33] D. Taylor, Geometrical effects in fatigue: a unifying theoretical model, Int J Fatigue, (1999), vol. 21, pp. $413-420$

[34] D. Taylor, A mechanistic approach to critical-distance methods in notch fatigue, Fatigue Fract Engng Mater Struct, (2001), vol. 24, pp. 215-22

[35] D. Taylor, P. Cornetti, N. Pugno, The fracture mechanics of finite crack extension, Engineering Fracture Mechanics, (2005), vol. 72, pp. 1021-1038

[36] E. Thieulot-Laure, S. Pommier, S. Fréchinet, A multiaxial fatigue failure criterion considering the effects of defects, Int. J. Fatigue, (2007), vol. 29, pp. 1996-2004 